\title{
Lenguaje, tweets y pantallas. Entre escrituras y visualidades*
}

LANGUAGE, TWEETS AND SCREENS. BETWEEN THE WRITTEN

AND VISUAL FORM

LÍNGUA, TWEETS E TELAS. ENTRE ESCRITURA E VISUALIDADES

\section{Sergio Roncallo-Dow** \\ Diego Mazorra***}

Cuadernos de Música, Artes Visuales y Artes Escénicas

/ Volumen 10 - Número 2 / julio - diciembre de 2015

/ ISSN 1794-6670/ Bogotá, D.C., Colombia / pp. 153-169

Fecha de recepción: 11 de junio de 2014 | Fecha de aceptación: 25 de marzo de 2015 | Disponible en línea:

18 de diciembre de 2015. Encuentre este artículo en

http://cuadernosmusicayartes.javeriana.edu.co/

doi:10.11144/Javeriana.mavae10-2.Itpe

* Este artículo procede de la investigación Límites de la identidad en la modernidad tardía: Reconfiguración de los mitos modernos y la vigencia de los meta-discursos, COM- 53-2011. El proyecto es financiado por el Fondo Patrimonial para la Investigación de la Universidad de La Sabana.

**Profesor de la Universidad de la Sabana.

***Profesor de la Universidad Externado de Colombia. 


\section{Resumen}

El propósito de este artículo es pensar la forma en la que se reconfiguran los modos escriturales en medio de los nuevos ecosistemas mediáticos. Partimos de una revisión del concepto de juego de lenguaje propuesto por Wittgenstein para, posteriormente, evidenciar el modo en el que Benjamin re-articula la idea de la escrituralidad y, desde allí, abordar el fenómeno de las posibilidades múltiples de la escritura en medio de un ecosistema particular como Twitter. En la parte final del texto se explora el modo como se desestabiliza la aparente solidez de lo escritural y se abre el camino para pensar en nuevas posibilidades semióticas.

Palabras clave: Twitter; escritura; semiosis; Walter Benjamin; Ludwig Wittgenstein; Marshall McLuhan

\section{Abstract}

The purpose of this article is to ponder about the way in which written modes are redefined under the new media ecosystems. We start from a revision of Wittgenstein's the language-game proposal and then we look at how Benjamin redefines the idea of the writing ability and, from that standpoint, we use those conceptual tools to explore the phenomena of manifold possibilities of writing within a particular media ecosystem, namely Twitter. The final part of the paper explores the way in which the seeming solidity of the written form is shaken and the path is set to think about different semiotic possibilities.

Keywords: Twitter; writing; semiosis; Walter Benjamin; Ludwig Wittgenstein; Marshall McLuhan

\section{Resumo}

O objetivo deste artigo é refletir sobre a maneira pela qual os modos de escrita são redefinidos no âmbito dos novos ecossistemas de mídia. Nós começamos com uma revisão do conceito de jogo proposto por Wittgenstein para, em seguida, demonstrar a maneira em que Benjamin re-articula a ideia de linguagem e alfabetização, a partir daí, para abordar o fenómeno de múltiplas possibilidades de escrita no meio de um ecossistema particular no Twitter. Na parte final do texto a forma como a aparente solidez da escrita torna-se instável e abre o caminho para pensar sobre a explorar novas possibilidades semiótica.

Palavras chave: Twitter; escrita; semiótica; Walter Benjamin; Ludwig Wittgenstein; Marshall McLuhan 


\section{¿TENÍA WITTGENSTEIN RAZÓN?}

Para ese extraño "segundo" Wittgenstein el lenguaje no era monolítico, siempre hay nuevos barrios, nuevos intersticios del lenguaje. Uno de estos nuevos barrios del lenguaje se presenta en la actualidad con sutiles transformaciones y apropiaciones de códigos tecnológicos por parte de comunidades organizadas en torno a la definición, nombrada, bien sea de redes sociales o comunidades virtuales, que conviven y se cruzan en el mapa de una ciudad más grande y vieja en la que aún existen calles antiguas que la lingüística toma como objeto de estudio.

López Cuenca ha visto precisamente este punto, y en su artículo "Formas de Vida: de Wittgenstein a las comunidades electrónicas" (2008) ha captado con particular agudeza una de las nociones clave para comprender no solo el problema de la continuidad de Wittgenstein sino una posible limitada interpretación por parte de Lash (2005). Aunque López se centra de manera más decidida en una suerte de defensa de la originalidad del pensamiento de Wittgenstein sobre las nuevas interpretaciones de la noción de forma de vida, logra asir con fuerza un punto que es fundamental: tanto en el primer Wittgenstein como en el de las Investigaciones hay una articulación del lenguaje basada en reglas. En el primer caso se trataría de las reglas de la sintaxis lógica, en el segundo de las — mucho más conocidas_ reglas del uso. Esto es clave en la medida en que se podría expandir y enriquecer un poco más la muy recordada cantilena wittgensteiniana a propósito de lo que significa seguir una regla y de su capital importancia para comprender el hecho mismo de que el significado estaría dado por el uso. ¿Hacia dónde nos llevaba ese segundoWittgenstein? Esta era esa nueva calle, ese nuevo sendero que se abría con la muy conocida apuesta wittgensteiniana de los juegos de leguaje que, lejos de ser una propuesta abstracta para pensar los modos de producción significativa del lenguaje, terminaría por convertirse en uno de los grandes lugares de pensamiento en el siglo XX. Tan grandes y tan rendidores en términos filosóficos que hoy son el punto clave para pensar las posibilidades del significado en los nuevos resquicios que se abren en la red. Esos juegos de lenguaje que nos permiten saber qué jugadas deben hacerse en cada momento y qué significa cada una de ellas. Hoy, en momentos en los que el signo se hace inestable en medio de las polisemias que se abren en medio de los nuevos ecosistemas de significación, se hace fundamental re-pensar los múltiples juegos de lenguaje que se tejen.

Recordemos qué es un juego de lenguaje en su versión más conocida, la trabajada en las Investigaciones: "Llamaré [...] 'juego de lenguaje' al todo formado por el lenguaje y las acciones con las que está entretejido" (2003, p. 25). ${ }^{1}$ Sin pretender hacer una exégesis detallada del concepto - pues esto desborda lo que aquí me propongo— bastaría empezar el recorrido haciendo énfasis en lo que significa jugar. No hay juego sin un otro con quien jugar. Los niños juegan con otros niños o con sus amigos imaginarios o consigo mismos haciendo las veces de otro, con sus otros creados por ellos y que fungen, diríamos, como condición de posibilidad del juego. Los adultos también juegan, de muchos modos. No necesariamente anclado a lo lúdico, la noción de juego puede ir acompañada de los más diversos epítetos: juego de mesa, juego financiero, juego sexual, juegos de guerra, teoría de juegos... el concepto desborda lo lúdico pero mantiene una constante con los juegos de los niños: la presencia de otro(s) (Roncallo-Dow, 2011).

Aparece una sugestiva idea de la interacción en las ideas mismas de Wittgenstein y que nos obliga a pensar desde una perspectiva más fenomenológica el problema de la significación 
en el momento en el que lo anclamos a la idea de las formas de vida y de interacción (se vive/ juega con el otro). Veremos qué sucede ahora en épocas en las que se hace cada vez menos clara la estabilidad oral y escritural del lenguaje mismo.

\section{IMÁGENES: JUEGOS, MOSAICOS Y REORDENAMIENTOS}

Y una nueva calle era la que se abría en el mundo cuando el modo de producción capitalista se asomaba a los nuevos escenarios de construcción de una burguesía basada en la transformación industrializada de materias primas. Los ritmos del acero modificaban los escenarios de la cultura, y además, el lenguaje mismo. Cuando el escritor y editor Roberto Calasso se sumergió en la Bodleian Library de Oxford para revisar los textos manuscritos de Kafka, encontró entre sus obras unos folios que pertenecían a una carpeta llamada "Los aforismos de Zürau", escritos entre 1917 y 1918 en la villa en la que vivía su hermana Ottla y que no eran más que una reunión de hojas sueltas, cuyo orden y género ya no era el de los aforismos, una ordenación fragmentaria y corta, ordenada ya no por temas o líneas de trabajo sino por ciertas afinidades que se identificaban por una numeración en apariencia caótica (Kafka, 2005 [2004]). Esta carpeta disímil, y sin embargo unificada por Kafka, lo lleva a aventurarse a la edición y publicación de "Aforismos de Zürau" de los que dice en su epílogo:

(...) tampoco la definición de aforismo es del todo acertada, si se entiende la palabra en el sentido corriente de 'sentencia'. Algunos de estos fragmentos son narrativos, otros son imágenes aisladas, otros son parábolas (...). Inútil comparar los aforismos de Zürau con alguna muestra del género anterior a ellos. La conformación resultaría siempre sesgada, como apoyada sobre una base inestable. (Calasso, 2005, pp. 144-145)

Sobre esta nueva calle también transitaban Wittgenstein y Benjamin. El primero, en la Introducción de las Investigaciones filosóficas comparaba su escritura con dibujos, puntos que se unen en distintos paisajes, algunos de ellos recortados y que terminaban adquiriendo esta forma: "Así pues, este libro es en realidad sólo un álbum" (Wittgenstein, 2003, p. 13). Los nuevos ambientes de producción material, la línea de montaje y el ritmo del acero también construían en Benjamin una escritura fragmentaria en la que experimentaba con diversos formatos, comparando, buscando una figura que le permitiera registrar la realidad. Así, fotografía, cine o radio serán parte de los modos de expresión de Benjamin en esos años. ${ }^{2}$

Esta forma de escritura se puede encontrar en los Denkbilder. la imagen-pensamiento, de Benjamin. Adriana Mancini, en la Introducción a los Denkbilder dice:

Por sus características, la palabra 'Denkbilder', referida a una forma de representación, permitiría sintetizar con mayor fidelidad la intención de los escritos de Benjamin, catalogados, en general, como aforismos. En un estudio más reciente, Andreas Huyssen (Huyssen, 2010) coincide en señalar la dificultad para definir desde una perspectiva genérica o poética estas formas breves de narración que exceden las formas tradicionales del fragmento, el aforismo o la parábola y que él llama 'miniaturas modernistas'. Son formas, señala, que se asocian a la transformación de las metrópolis del siglo XIX, como Viena, París o Berlín, así como también a la descomposición del imperio alemán y austro-húngaro. $\mathrm{O}$ 'antiformas' precisa Huyssen (...). (Mancini, 2011, p. 8) 
Las imágenes que piensan se articulaban de la mejor forma con ese modo de experiencia del mundo de Benjamin que se podría encontrar en su apuesta por la "imagen dialéctica". Al entrar a observar Benjamin las relaciones de la modernidad desde Baudelaire, en la que aparecía París como una ciudad que se erigía con un "substrato social moderno", perdida y hundida, decía Benjamin:

Aquí ocurre esto mediante la ambigüedad característica de las relaciones y productos sociales de esta época. La ambigüedad es la presentación plástica de la dialéctica, la ley de la dialéctica en reposo. Reposo que es utopía, y la imagen dialéctica, por tanto, imagen onírica. Semejante imagen presenta la mercancía en última instancia: un fetiche. Semejante imagen presentan los pasajes, que son tanto casa como calle. Semejante imagen presenta la prostituta, vendedora y mercancía en uno. (Benjamin, 2005, p. 45)

Para Beatriz Sarlo, la experiencia del mundo de Benjamin, que construía el conocimiento y el sentido por un "contraste iluminador" es el método mismo de pensar de Benjamin:

La forma de la evidencia histórica, piensa Benjamin, se encuentra en las imágenes que condensan, como la iluminación poética, elementos muy lejanos, cuyo vínculo era secreto pero no inmotivado. Esta distancia que la imagen establece y, al mismo tiempo, anula, es filosófica y metodológica. En efecto, el 'método Benjamin' (si se permite esta expresión inusual para su objeto) es, como la estrategia surrealista, una aproximación entre dos registros que, cada uno en sí mismo ha perdido su verdad, pero cuya contraposición instituye un sentido. (Sarlo, 2007, pp. 26-27)

Un ejemplo de estas "Imágenes que piensan" de Benjamin se publica dentro de sus Denkbilder en un texto en homenaje a Hugo von Hofmannstahl, que apareció publicado por primera vez el 23 de agosto de 1929 en el Frankfurter Zeitung titulado “San Gimignano". En el texto se lee:

Encontrar palabras para lo que tienes ante los ojos puede ser muy difícil. Si al fin llegan, golpean con pequeños martillos lo real, hasta que han expulsado de ahí a la imagen como al irla borrando de un placa de cobre. 'Por la tarde se reúnen las mujeres, en torno a aquella fuente que queda ante la puerta de la ciudad, a coger agua con sus grandes cántaros': sólo cuando encontré estas palabras, la imagen desapareció de lo vivido demasiado brillante y ciegamente, con sus recios bultos y sombras profundas. (Benjamin, 2010, p. 312)

Así, la figura de producción del grabado en aguafuerte es la forma de escritura que copia Benjamin, las palabras como el cincel que desnudan la imagen pensamiento, esa miniatura moderna de la época material a la que pertenece: la que eleva la fotografía sobre las bases del grabado en cobre y el daguerrotipo. El propio libro Calle de dirección única avanza con la mirada de la fotógrafa Asja Lacis, se adentra Benjamin en Nápoles y Moscú. La forma de la escritura era también el contenido de los cambios que el capitalismo había realizado sobre las ciudades, las mercancías, el lenguaje.

Como dice Walter Benjamin en "La obra de arte en la época de reproductibilidad técnica": "The way in which human perception is organized — the medium in which it occursis conditioned not only by nature but by history" (Benjamin, 2008, p. 23). El poeta Hugo 
von Hofmannsthal, a quien dedicaba Benjamin la imagen pensamiento ya citada, escribía en un poema:

Si separáis la forma del contenido, no sois artistas que crean.

La forma es el sentido del contenido, el contenido la esencia de la forma. ${ }^{3}$

Esta idea en términos más anclados a la reflexión tecno-lógica, sería retomada por McLuhan, quien

(...) desarrolló una comprensión fenomenológica de la cultura (...), podemos observar que

(McLuhan) se mueve de una noción de cultura como el paisaje hacia una que la concibe como

entorno / (medio) ambiente (environment). (Marchessault, 2005, p. xii)

Ahora bien, la comprensión de esta idea de entorno / (medio) ambiente es, para McLuhan, bastante particular, toda vez que no denota una suerte de contenedor; cuando McLuhan señala en Counterblast que el (medio) ambiente "es un proceso y no contenedor", intenta mostrar que "el efecto de todas las nuevas tecnologías es imponer, silenciosa y penetrantemente, sus particularidades muy profundamente en la psique humana reelaborando la ratio misma de los sentidos" (Roncallo-Dow, 2014, Strate, 2015). Como lo muestra el mismo McLuhan:4

Cuando

esas

percepciones

cambian,

\section{los hombres cambian}

(1997, p. 41).

Los medios, al modificar el ambiente, suscitan en nosotros percepciones sensoriales de proporciones únicas. La prolongación de cualquier sentido modifica nuestra manera de pensar y de actuar -nuestra manera de percibir el mundo.

La forma también tenía que ver con el contenido, y con cierto espíritu o sensibilidad de época. Por ejemplo, en Calle de dirección única de Benjamin, se reflexiona sobre la literatura basada en hechos y la basada en convicciones, siendo la primera la que alterna acción con escritura, más fuerte en las comunidades más activas y la cual se basaba en formatos que no son el libro, como el folleto, artículos de revista, carteles, octavillas. Estos formatos definían el contenido, no solo en ellos sino en la sociedad:

Sólo este rápido lenguaje puede surtir un efecto que se encuentra a la altura del momento.

Para el aparato gigantesco de la vida social, las opiniones son lo que el aceite es para las máquinas... (2010, p. 25).

Es en medio de esta disolución del individuo que nace la idea del flâneur de Baudelaire; el habitante de la ciudad fragmentada. El flâneur es el individuo desarraigado, carente de territorialidad, es aquel que no habla el mismo lenguaje que su entorno. Al no hablar, solo le queda una alternativa: observar y describir en su propio lenguaje aquello que ve. Es él quien se atreve a asomarse bajo la mismidad de la multitud y aprehender las múltiples diferencias que allí subyacen. Hay una comunicación asimétrica entre el flâneur y su entorno, pero es la ciudad quien no lo comprende, por eso el único camino es la flanerie. El flâneur se distancia 
de la ciudad, no se siente parte de ella, busca desaparecer, mientras observa y encuentra lo inesperado, aquello que solo él puede ver.

La plaza como punto de encuentro ha desaparecido. Cuando la ciudad se dispersa, el individuo se transforma en masa y quienes se niegan a pertenecer a ella se encuentran en medio de una realidad que les es extraña. El flâneur de Baudelaire es un hombre moderno, tan moderno y tan disperso como Juan Pablo Castel, quien deambula por las calles de Buenos Aires totalmente ajeno a lo que a su lado acontece. Las nuevas formas de escritura que aparecían en la ciudad, como las "physiologies", imitan la actividad del escritor pequeño burgués que convertido en flâneur se para en el mercado y observa un panorama que convierte en pequeñas miniaturas anecdóticas. Con el fin de la burguesía monárquica, las fisiologías se transforman y pasan a ser fisiologías de los pueblos o de la ciudad. Los primeros mapas para el flâneur que se movía en los pasajes del comercio industrial.

Benjamin compara entre la obra de arte, en las que forma y contenido son lo mismo: la sustancia; y un documento que es dominado por la materia, densa de formas desperdigadas y que "sólo nos domina mediante la sorpresa". Cada vez más, el cambio de una comunidad -que en previas escrituras de "La obra de arte en la época de su reproductibilidad técnica" Benjamin denomina como histórica— se relaciona con el cambio en la percepción del mundo, y este se puede rastrear en sus nuevas formas literarias de ver y describir el mundo que lo rodea.

Para Benjamin:

Al interior de grandes intervalos históricos, junto con los modos globales de existencia que se corresponden a los colectivos humanos se transforman también, al mismo tiempo, el modo y la manera de su percepción sensible. Pues el modo y la manera en que la percepción sensible humana se organiza — como medio en el que se produce — no está sólo natural sino también históricamente condicionado. (2008, p. 56)

Esto eran las fisiologías. Hoy podemos decir que el escritor, una vez hubo puesto su ojo en las pantallas panorámicas del mercado posindustrial basado en el intercambio de información, miró en derredor con su scroll hacia debajo de los hilos de código, como en un panorama, y sus primeros intentos de orientación los captaría en un género literario propio: la literatura de hilos.

\section{EL TIMELINE, LOS THREADS (Y, CLARO, EL \#)}

Hoy aparecen nuevos barrios de lenguaje en la producción de sentido de una construcción masiva de prosumidores de imágenes dialécticas, que reinterpretan pasado, presente y futuro. Novedad relacionada con el mercado mundial que se mueve cada vez más en el intercambio digital de información por el mundo. Cada intercambio de ceros y unos en la banca mundial apareja un intercambio de ceros y unos en correos electrónicos, mensajes de texto, fotografías, videos y otros viejos contenidos de producción que hoy se mezclan bajo la nueva forma de la pantalla.

Benjamin había visto una aparición similar en las fisiologías o cuando en Calle de dirección única, con algo de nostalgia se declaraba "Tenedor jurado de libros", mientras observaba cómo la escritura "se va adentrando en el espacio gráfico de su nuevo carácter figurativo excéntrico..." (2010, p. 43). En ese momento la acumulación de imágenes es lo que daba sentido al cine, esa imagen movimiento, que hoy aparece en formato videoclip en las ciudades que describe García Canclini. El zapping del televisor se oculta en el pasar del timeline. Ya no 
puede haber totalidad, solo detalles y fragmentos. Pero ojo: tal como en los "aforismos" de Benjamin, hay un sentido común, un aire familiar, de la misma forma en Twitter hay diálogos, hay una historia. Esta historia se le conoce en foros de Internet profunda como 4chan (http:// www.4chan.org) con el nombre que los ingenieros informáticos le dan a los procesos ligeros que en un sistema incluyen sus propias subrutinas con códigos y contextos particulares. En español se conoce a estos subprocesos como hilos de ejecución que conforman el todo de un sistema operativo. Esa es la base material de intercambios de información.

En las redes sociales, esos sistemas operativos sociales (a la manera de entenderlos de Lee Rainie) permite la construcción de diversos foros en comunidades. A la manera de 4chan, se producen por los usuarios diversos threads que son debatidos a manera de conversación entre los usuarios de una red social. En la última actualización de Twitter, por ejemplo, estos hilos se pueden ver en la delgada línea azul que conecta diversas respuestas en torno a post propuesto en la red social. A medida que se recorre la pantalla hacia abajo, la conversación por hilos aparece por doquier, una nueva forma y un nuevo contenido en que predomina la imagen en la construcción de sentido (Figura 1).

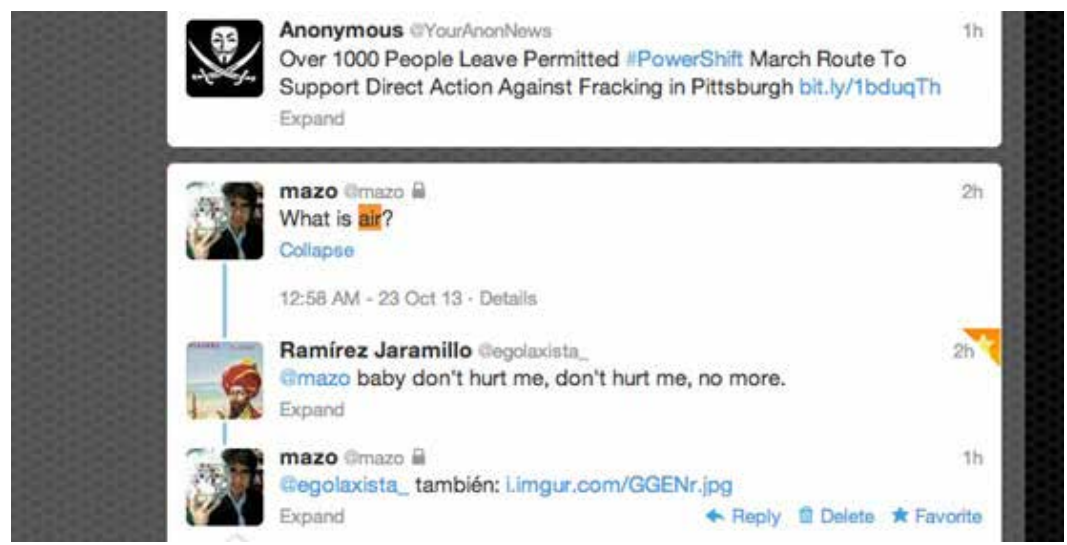

Y esta imagen, que de forma acumulativa produce sentido, también se orienta a contener en ella rastros de las viejas formas y contenidos. Uno de los threads más famosos en 4chan es el que reconvierte los viejos capítulos de la serie animada de televisión del hombre araña en los años sesenta en pequeñas imágenes que cada usuario reinterpreta para dar sentido a las conversaciones que ahí se establecen (Figura 2).

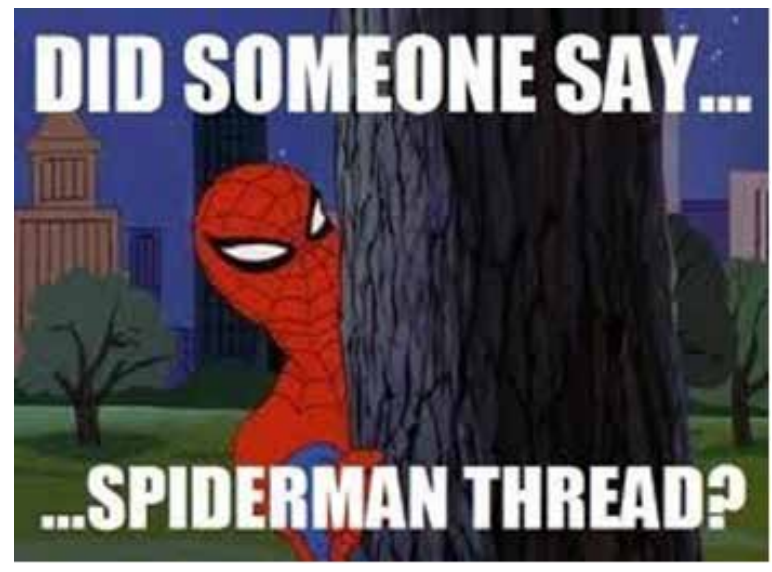


La línea de tiempo, hoy transformada en hilos de conversación representados en Twitter en esa línea azul, mezcla de conversación oral y links compartidos (muchos de ellos con imágenes) es la nueva forma de literatura del paseante asiduo de las redes sociales.

La red también se encuentra formada por las condiciones materiales que permiten el almacenaje constante de información. No todo es virtual, los servidores son reales así como los discos duros de gran capacidad que almacenan los datos que aparecen luego en la llamada nube. La forma de organizar la información ha cambiado. En las sociedades postindustriales cada vez se habla más de la "información", los datos, unidos a conocimiento e innovación, como el nuevo escenario de la producción, el que antaño tuvieron las materias primas en la producción capitalista de la revolución industrial. Hoy gana más el que produce información, de ahí lo importante de su almacenamiento; bytes, terabytes, etcétera permiten almacenar gran cantidad de información (esta es la materialidad de las redes como Internet, siempre requieren de servidores, de discos duros gigantes que almacenan miles de millones de bytes en el mundo que quedan al descubierto en la cantidad de información que manejaban empresas especializadas en este almacenamiento de datos como Megaupload). Esta materialidad es la que de forma mimética se muestra en Twitter: el almacenaje de miles de millones de tweets en un solo hashtag.

El \# se ha convertido hoy en toda una forma de escritura por hilos del almacenaje de información. Se puede medir su tamaño de almacenamiento por la cantidad de tweets relacionados con un \# en un tiempo definido \#. Estos son los threads en los que vale la pena estar, las novedades, la mayor asimilación de imágenes y textos en distintas pantallas que producen sentido dentro de una comunidad. Los llamados trending topics no son más que datos almacenados que se convierten en threads de largo aliento en una temporalidad corta y que aún cargan en su espesor simbólico la carga del lugar, el espacio físico. Hoy los trending topics se organizan en twitter por medio de la ubicación geográfica del usuario (Figura 3).

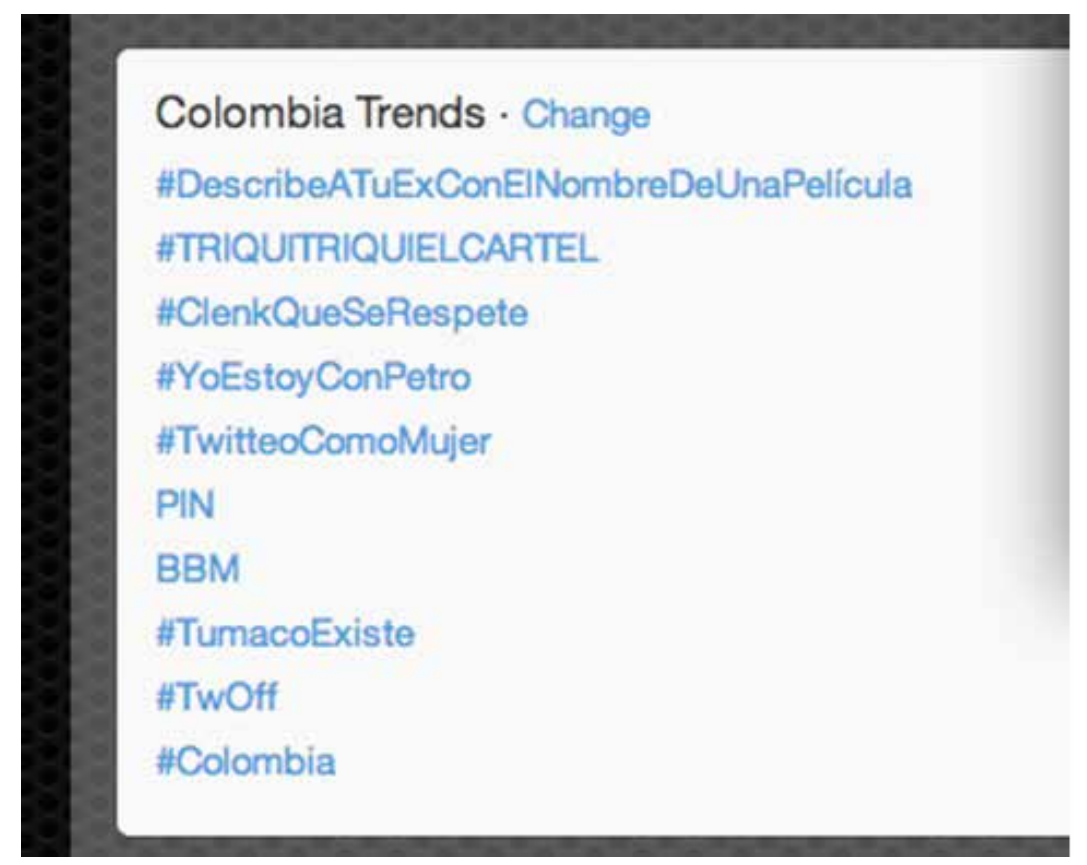




\section{EL RETWEET}

Beatriz Sarlo, en sus siete ensayos sobre Walter Benjamin comenta sobre las ruinas de la escritura del gran edificio que nunca fue: "El libro de los pasajes" que Benjamin, como gran conversador, le daba un lugar importante a las citas para iluminar en el pasado el futuro, esa base de la imagen dialéctica (2007, p. 27). "Para Benjamin el arte de la escritura se une al de citar" dice Sarlo. La gran obra en construcción que es "Los pasajes" se conforma por una acumulación de citas, cuyo sentido se da en la interrelación. Así también entendía Benjamin su escritura acorde a los nuevos modos materiales de reproducción del capital, como en el caso de la acumulación de imágenes en el cine. Para un twittero común, el arte de la escritura se une al del retweet. Dice Sarlo:

Imagen y aforismo como forma de la exposición: desde allí podría también pensarse a Benjamin como romántico o como lector de Nietszche y del vienés Karl Kraus, escritores cuyo pensamiento tampoco pudo prescindir del aforismo. (2007, p. 31)

En twitter el llamado RT (manual) o retweet automático, se convirtió en la evolución de esta red social en un subproceso por derecho propio. La escritura del retweet se reproduce en cada usuario, y en su timeline. Son grandes subprocesos que aparecen en la red. La cita de la cita, que a través de las distintas producciones construye sentido, muchas veces ubicado a un paso de la ironía cuando se atribuyen citas textuales a quien no lo dijo. Algo similar ya había ocurrido en el mundo del arte que se reproducía mecánicamente, como en la figura (Figura 4) de Banksy:

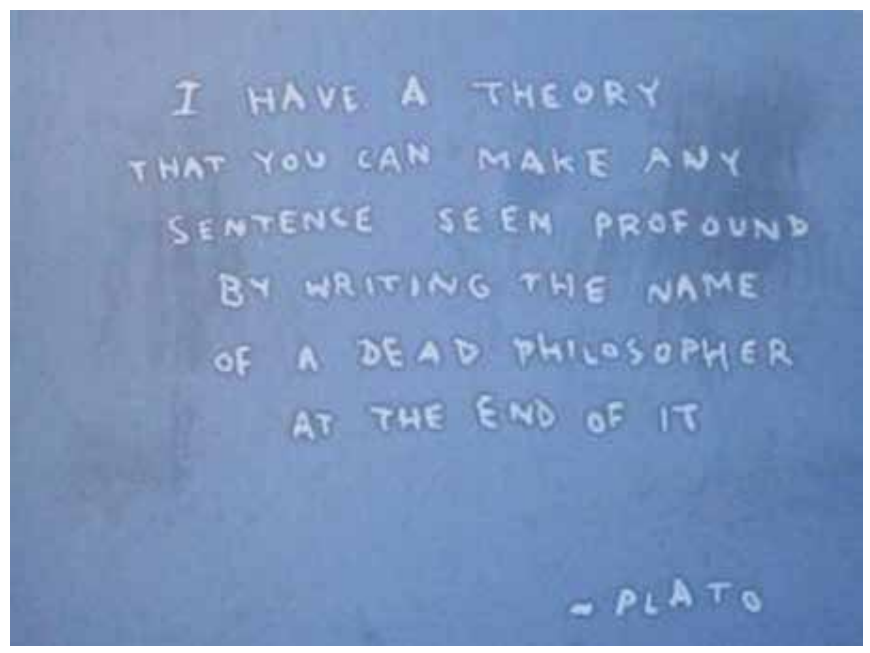

\section{LAS IMÁGENES (II)}

La mímesis que se produce en la experiencia del ser humano con relación a la modernidad y su técnica hace hincapié en Benjamin en la noción de fantasmagoría y de imagen dialéctica. Es en las imágenes en las que se puede apreciar la experiencia de una época y a través de ellas se puede no solo reinterpretar el pasado, sino ver las fuerzas materiales que impulsan su desarrollo en el presente y el futuro. Margaret Cohen dice: 
Desde la primera obra del ciclo [la autora llama a esto el ciclo de producción parisina de Ben-

jamin], Calle de dirección única, Benjamin busca diferenciar sutilmente las equivalencias entre ilusión visual e ilusión ideológica apelando a la incidencia histórica, y sería ilustrativo examinar en detalle sus representaciones de los estereoscopios, panoramas, dioramas y de los primeros procedimientos fotográficos y cinematográficos a la luz de ese interés. En términos generales, podríamos decir que Benjamin invoca estos espectáculos para investigar la manera en que —como diría Marx - el contenido va más allá de la frase. (2010, p. 216).

El espectáculo de la sociedad hoy, con una "recepción en la dispersión" (Eiland, 2010), se observa en las imágenes. Desde las páginas de comentarios de los diarios de circulación digital podemos observar cómo el comentario clásico de texto escrito se ve reemplazado en su contenido por una mezcla de viejas imágenes de televisión convertidas en memes. Las imágenes se toman los foros, las redes sociales como Instagram comparten imágenes como si fueran escritos. El contenido del debate público hoy pasa también por la imagen. Redes como Vine suplantan la televisión, el timeline de twitter se llena de pics, y la pregunta a qué estás haciendo se responde hoy con una fotografía.

Las nuevas formas de percibir el presente son nuevas formas de ver $t v$, leer noticias, escribir historias, narrar acontecimientos pasan hoy por escribir imágenes. Michael Jennings menciona que la escritura de Benjamin era constructivista, buscaba incorporar materiales reales de objetos industriales a objetos culturales, como en los pasajes. De la misma forma hoy Twitter busca incorporar materiales de objetos postindustriales, los datos y la información a su escritura; así, las imágenes simulacro pueblan en pictwitter o Instagram la conversación:

El aporte constructivista de Benjamin a la "Nueva visión" que cobró forma en la fotografía y el cine alemanes a mediados de los años veinte fue, por lo tanto, una forma literaria. Su texto, en su lenguaje magro e incisivo, en su carácter refractario y diagramático y en su concepción de la escritura como prótesis humana necesaria, busca ejemplificar —más que limitarse a describir- el papel que Moholy-Nagy reclama para los nuevos medios tecnológicos: la capacidad de alterar los modos de percepción humana mediante la exposición a relaciones nuevas y 'productivas' entre la compleja multiplicidad de los objetos de la sensación humana en la modernidad. (Jennings, 2010, pp. 44-45).

La materialidad de los bytes, su almacenamiento, permiten hoy las bases de datos; el lenguaje modal de los nuevos medios que relata Manovich permite su intercambiabilidad; Twitter, como parte de esta nueva ecología mediática se apropia entonces también de la escritura literaria (Pola Oloixarac con su novela fragmentaria es solo un ejemplo), pero también se apropia del periódico, de los noticieros de tv, de los videojuegos. Si la forma del cristal y el acero, elementos básicos de la producción capitalista, daba forma a los pasajes y a la percepción particular del paseante en París, en estos momentos la materialidad de los bytes y el lenguaje del programa informático son la forma del contenido del viejo medio: la imagen, la televisión.

\section{EL LENGUAJE Y TWITTER}

Para Benjamin la relación del lenguaje con el mundo era la capacidad del hombre de nombrar las cosas (idea que se deriva de su pensamiento teológico). El hombre, gracias a su capacidad mimética, veía el lenguaje de las cosas que se encontraba en su capacidad de comunicar y las nombraba. El lenguaje era todo aquello que podría ser nombrado, y por tanto 
independiente de las cosas mismas. Una estructura teológica de la existencia de un lenguaje que el hombre aprovechaba por su capacidad de nombrar el lenguaje en el mismo lenguaje.

Wittgenstein partía de la misma reflexión sobre el nombrar las cosas que hallaba en San Agustín y añade un escalón: no solo es el nombre de las cosas, es su uso. El nombrar cosas hoy en redes sociales, adjuntarles sentido a través de un \#, organizarlas por un thread, resignificarlas en las citas comunes o las imágenes, es una expresión del nuevo lenguaje de las cosas, un lenguaje casi matemático (no hay que olvidar los grandes esfuerzos que hacen los primeros blogueros por escribir sus post aprendiendo a hablar en HTML y a nombrar las cosas desde el código o la mímesis de las expresiones de códigos informáticos como thread para volver a nombrar los foros) afianzado en las nuevas formas materiales de relacionar las cosas y en las nuevas formas materiales de producción capitalista.

Pero este nombrar ya no sólo es la capacidad mimética del lenguaje primitivo, va más allá, poco a poco se está convirtiendo en la capacidad mimética del capital y el materialismo de apropiarse del lenguaje humano. Y más allá, las cosas nombradas ahora también tienen su uso: cada vez que se nombra en Twitter, se añade un \# o un thread, esto es parte de un subproceso, de un uso que conforma a la red social en su conjunto, formada por infinidad de hilos relacionados unos con otros y dispersos en un enorme sistema operativo mundial, del que Twitter es un ejemplo.

Markus, al comentar sobre la teoría de la experiencia en Benjamin, asume el pensar en una historicidad radical; dicha experiencia incluía la organización de los sentidos de la percepción del ser, y el medio en el que se puede ver esto no solo es natural sino socialmente condicionado: el lenguaje. "Benjamin found the key to and model of this changing organization and mode of experiencing ultimately in language" (2001, p. 13). Además, Markus enfatiza que la experiencia se basa en la capacidad mimética del ser humano que puede ser expresada en el lenguaje, por lo que lenguaje no solo sería una asignación arbitraria de signos y símbolos, sino también la aprehensión mimética del mundo, por lo que entender a un interlocutor no solo implica su asociación de palabras en una estructura gramatical, sino también cosas como el tono de voz, la manera de hablar, las referencias al mundo que se encuentran en y a través del lenguaje. Por esta razón se asimila este estudio al de los cambios históricos, que pueden entenderse no solo como lo que fueron sino en el cómo se vivieron. Así, estudiar las ruinas es estudiar una forma de sentir la experiencia del mundo, y de ahí que el método de la imagen dialéctica sería volver a estudiar esta experiencia del mundo (Markus, 2001).

Este proceso de mímesis en el que se observa la noción de lenguaje en Benjamin, se da para Markus en la forma que toma la mercancía. Markus se propone entonces observar en los fragmentos sueltos del pensamiento de Benjamin este proceso mimético:

Benjamin's relative lack of attention to commodity as a specific type of the organization and integration processes of production and exchange which increasingly drags into is orbit many branches of cultural activity and impacts all of them. He does make a number of acute observations related to this topic. He points, for example, to changes in literary genres and styles which follow upon the fact that the rivalry among poets now takes the form of competition on an open market. (2001, p. 15)

Así, elementos de la cultura adoptan la forma fantasmagórica de la mercancía. Y hoy la forma que adopta la mercancía y su circulación se encuentra relacionada con la producción de información. 
Kang Jae-Ho discute la aparición de la experiencia en esta fantasmagoría desde su ensayo sobre la reproductibilidad técnica de la siguiente forma:

Benjamin's recognition of experience as historically specific and technologically conditioned enabled him to avoid the shortcomings embedded in the dichotomy between Erfahrung and Erlebnis and led him to systematically examine the process of the reproduction of social relations. (2005, p. 247).

Entender entonces los cambios en la percepción generados por una experiencia moderna en el momento de Benjamin, y traerla al mundo de la aldea global requiere ver las diferentes formaciones de los sujetos y su experiencia, los modos de comunicación (que han pasado hoy de lo impreso a lo electrónico) y las facultades relacionadas como mímesis, remembranza y olvido (Kang, 2005, p. 248). El estudio entonces de la época de reproductibilidad técnica para Kang no radica en una teoría del arte sino de la percepción (Zegarra, 2009).

Para Zegarra, esta época de la fantasmagoría en que la vorágine del progreso empieza a repetir por virtud técnica la mercancía desplazaba los modos tradicionales, como la fotografía desplazaba el contenido aurático de la pintura, cambia la concepción misma de la imagen, que se desplaza de la representación mental a un "síntoma epocal: las imágenes de Benjamin nos muestran el mundo, la Europa fantasmagórica que vivía el ensueño de las nuevas tecnologías" (Zegarra, 2009).

Es en este escenario que Zegarra relaciona la experiencia y la fantasmagoría en Benjamin con el pensamiento de McLuhan:

Me parece que esta precisión mcluhaniana sobre la necesidad de no escindir el medio del mensaje es algo que está ya supuesto en la idea de imagen que desarrolla Benjamin. Al presentarnos la decadencia del aura, Benjamin nos aproxima también a un nuevo método para notar ese proceso. En esto radica lo paradójico e interesante de su postura: él quiere ofrecernos un montaje que permita una mirada crítica de la fantasmagoría, pero lo hace, justamente desde la estructura de un modo de pensar ya marcado fantasmagóricamente. No digo aquí que Benjamin fuera un pensador que se acercaba a la realidad en clave cosificante o mercantilista, lo que sostengo es que ante la presencia masiva de ese modo de ser desprovisto de profundidad y solo capaz de lo homogéneo, Benjamin se esmera en romper con la linealidad del discurso para ofrecer pequeños destellos que despierten la capacidad crítica de la masa. Así, contra la actitud irreflexiva y desatenta, su pensamiento se vuelve fragmentario, plantea su crítica desde la sugerencia borrosa, a través de la nubosidad de la imagen de pensamiento. Cuando se han terminado las palabras, cuando el discurso ya no cala más en la masa que ha sido anestesiada por la mercancía y por la uniformización de todo valor, cuando son así las cosas, se vuelve necesario ofrecer otro acceso que cautive de un modo que lo previo ya no logra hacerlo. Benjamin no termina siendo otra cosa que el vivo testimonio de que el medio es el mensaje y de que los nuevos medios ya estaba reconfigurando su propia forma de pensar. (Zegarra, 2009)

En la capacidad mimética del lenguaje del hombre, en una tradición de pensamiento que viene desde San Agustín, encontramos que dicha mímesis hacía parte del pensamiento mismo de Benjamin. Esa mímesis nos permitía acercarnos al pensamiento de la época a través de la percepción de la misma. Las condiciones materiales hacían parte del lenguaje mismo; en la época de la industria del cristal y el acero cambian las formas mismas de los géneros 
literarios y las transformaciones materiales en los pasajes dan origen a una nueva forma de percepción de la ciudad.

Hoy, esa misma noción de lenguaje nos sirve para integrar los cambios materiales en la producción capitalista asociada a la información con el lenguaje mismo en el que se expresa. Palabras propias de los programas informáticos como threads, pic, entre otras, empiezan a vincularse al lenguaje cotidiano; las imágenes fragmentarias son hoy parte de conversaciones y lenguajes; en muchas de esas imágenes, como el reconocido thread de Spiderman podemos apreciar el uso de los viejos contenidos como imágenes que hablan del presente y el futuro. Redes sociales como Facebook, Twitter, Instagram son así ellas mismas expresión material de las nuevas formas de producción, y en ellas los contenidos que se exponen hacen parte de esta misma lógica de conversaciones modulares, fragmentarias, basadas en el imperio del medio que se desplaza como la imagen, organizadas como los procesos informáticos en hilos de conversación y que están generando una nueva forma de percepción, un nuevo sensorium en el que la imagen predomina en el discurso público, la vida privada cada vez se expone más y más, el lenguaje adopta los hechos ocurridos, y no solo se habla de threads o hashtag, sino que aparecen nuevos verbos como "tuitear", que influyen en la percepción de esferas tan alejadas como las políticas nacionales.

Y tal vez el escenario de cambio más importante es la percepción misma de los sujetos: no soy hombre, soy tuitero, o no soy parte de un foro, soy /b/, son definiciones que hoy alcanzan la nueva percepción de comunidades unidas bajo la lógica material del intercambio de información. Hoy en día, son las propias redes las que adquieren identidad. En el año 2010, en los foros de la red social Tumblr, reconocida por su fondo azul y especializada en el intercambio de imágenes en lugar de las tradicionales entradas de texto de los blogs, los "post" que ahí se hacían copiaban y reproducían hasta la saciedad (como el "cáncer") algunas creaciones que compartían lo usuarios de 4chan. En ese momento los usuarios de 4chan, reconocidos por el foro de Anonymous, que se escriben en letras verdes sobre el fondo rosado del foro, declaran la guerra de imágenes con la "Operation: overlord". Menos de unas horas después Tumblr responde con la "Operation: Overkitten" en la que inundarían de fotografías de gatos los foros de 4chan. Tras las primeras imágenes, las mismas comunidades se dieron a sí mismas una identidad virtual nueva, una personalidad. 4chan usaría el traje y la corbata negra de los reconocidos hackers de Anonymous, pero con el rostro verde sin marcas de identidad; Tumblr sería la niña hipster de cabello azul (Figura 5).
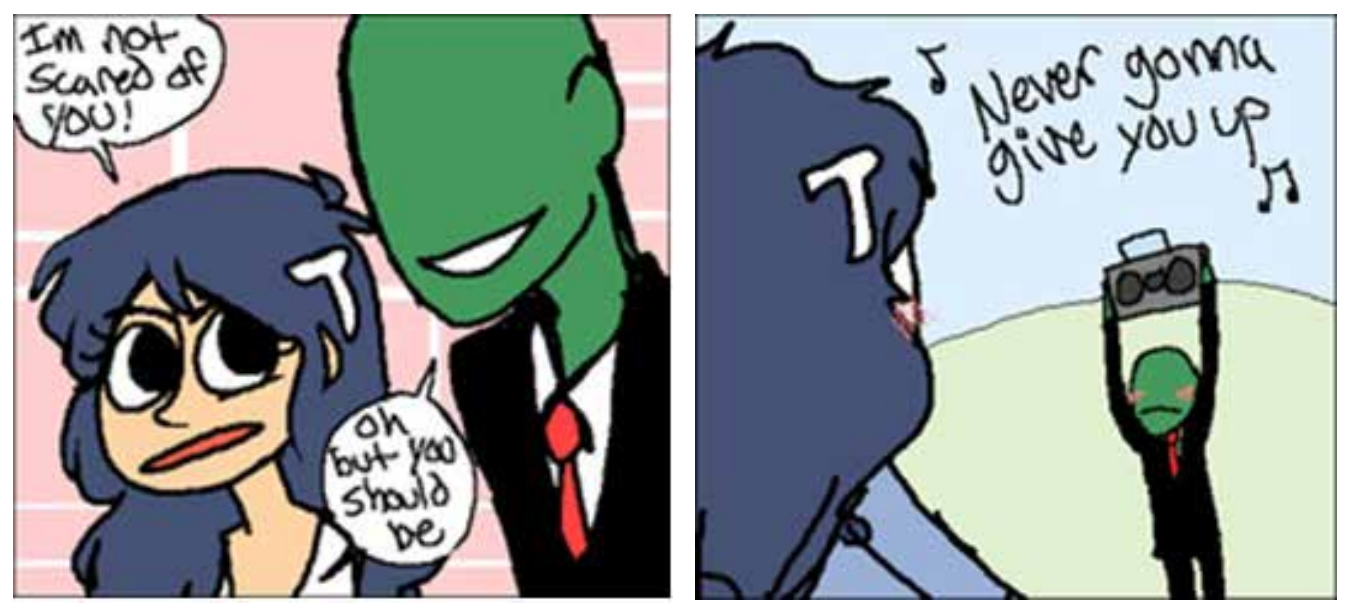
Los nuevos modos de percepción anuncian también nuevas formas de construir comunidad, una comunidad de alta exposición privada en la que las formas de nombrarse y ser pasan por los mismos registros de la creación de perfiles en redes sociales. La política y las propias redes sociales adquieren hoy en día las lógicas del debate por imágenes, de la conversación por imágenes y de la definición personal por imágenes. El contenido de las nuevas formas de percepción pasa por la modernidad capitalista.

\section{NOTAS}

1 Afirma, además, Wittgenstein en Investigaciones Filosóficas 23:

“¿Pero cuántos géneros de oraciones hay? ¿Acaso aserción, pregunta y orden? - Hay innumerables géneros: innumerables géneros diferentes de empleo de todo lo que llamamos 'signos', 'palabras', 'oraciones'. Y esta multiplicidad no es algo fijo, dado de una vez por todas, sino que nuevos tipos de lenguaje, nuevos juegos de lenguaje, como podemos decir, nacen y otros envejecen y se olvidan. (Una figura aproximada de ello pueden dárnosla los cambios de la matemática).

La expresión 'juego de lenguaje' debe poner de relieve aquí que hablar el lenguaje forma parte de una actividad o de una forma de vida.

Ten a la vista la multiplicidad de juegos de lenguaje en estos ejemplos y en otros:

Dar órdenes y actuar siguiendo órdenes -

Describir un objeto por su apariencia o por sus medidas-

Fabricar un objeto de acuerdo con una descripción (dibujo)—

Relatar un suceso -

Hacer conjeturas sobre el suceso -

Formar y comprobar una hipótesis -

Presentar los resultados de un experimento mediante tablas y diagramas-

Inventar una historia; y leerla-

Actuar en teatro-

Cantar a coro-

Adivinar acertijos-

Hacer un chiste; contarlo-

Resolver un problema de aritmética aplicada-

Traducir de un lenguaje a otro-

Suplicar, agradecer, maldecir, saludar, rezar-.

Es interesante comparar la multiplicidad de herramientas del lenguaje y de sus modos de empleo, la multiplicidad de géneros de palabras y oraciones, con lo que los lógicos han dicho sobre la estructura del lenguaje. (Incluyendo al autor del Tractatus logico-philosophicus)".

2 Philippe Baudouin, por ejemplo, acerca los experimentos radiofónicos de Benjamin a una aproximación filosófica de la estética de la creación radiofónica, contraponiendo la crítica de Heidegger, que criticaba esa masa de escucha radiofónica como un espectro, una fantasmagoría, a la forma de entender la radio como una obra de arte en el marco de la práctica de la obra filosófica de Benjamin, en especial de su ensayo "La obra de arte en la época de la reproductibilidad técnica". Así dice: "Pour Heidegger, la radio crée ainsi une communauté factice, virtuelle dirions-nous aujourd'hui, où les véritables questions ne sont pas traitées mais vienent plutôt 'nous hanter sous une forme spectrale' (R. Arnheim, Radio, Paris, Van Dieren, 2005, p. 17). Doit-on pour autant denier à la piece radiophonique la possibilité d'une approche philosophique? Penser la radio sous le signe de l'art: tel est le dessein d'une approche esthétique de la creation radiophonique" (Baudouin, 2009, p. 10).

3 Trennt ihr vom Inhalt die Form, so seid ihr nicht schaffende Künstler. Form ist vom Inhalt der Sinn, Inhalt das Wesen der Form. (Hugo von Hofmannsthal, 2002, p. 221).

4 Dadas las características visuales del todo particulares con las que McLuhan presenta sus ideas en El Medio es el Masaje reproducimos el aforismo tal como aparece en el texto original. 


\section{REFERENCIAS}

Baudouin, Phillippe. Au microphone: Dr. Walter Benjamin. Walter Benjamin et la création radiophonique 1929-1933. Paris: Éditions de la Maison Des Sciences de L'homme, 2009.

Benjamin, Walter. Calle de dirección única. En Obras (Vol. IV). Madrid: Abada editores, 2010.

Benjamin, Walter. Denkbilder. Epifanías en viajes. Buenos Aires: El cuenco de plata, 2011.

Benjamin, Walter. Illuminations. Essays and Reflections, ed. Hannah Arendt. New York: Schocken Books, 2007 [1968].

Benjamin, Walter. Libro de los pasajes, ed. R. Tiedemann. Madrid: Akal, 2005.

Benjamin, Walter. Obras (Vol. I). Madrid: Abada editores, 2008.

Benjamin, Walter. Obras (Vol. IV). Madrid: Abada editores, 2010.

Benjamin, Walter. Reflections. Essays, Aphorisms, Autobiographical Writings, ed. P. Demetz. New York: Schocken Books, 2007 [1978].

Benjamin, Walter. The work of art in the age of its technological reproductibility and other writings on media, eds. M. W. Jennings, B. Doherty, \& T. Y. Levin. Cambridge, Massachusetts; London, England: The Belknap Press of Harvard University Press, 2008.

Buck-Morss, Susan. The Dialectics of Seeing. Walter Benjamin and The Arcades Project. Cambridge, Massachussets; London, England: The MIT Press, 1991 [1989].

Calasso, Roberto. “El esplendor velado." En F. Kafka, Aforismos de Zürau. Madrid: Sexto Piso, 2005. 111-161.

Cohen, Margaret. "La fantasmagoría de Walter Benjamin". En Cohen, Margaret, y otros. Walter Benjamin: culturas de la imagen, ed. A. Uslenghi. Buenos Aires: Eterna Cadencia Editora, 2010.

Cohen, Margaret, y otros. Walter Benjamin: culturas de la imagen. Ed. A. Uslenghi, Buenos Aires: Eterna Cadencia Editora, 2010.

Eiland, Howard. "Recepción en la dispersión." En Cohen, M. y otros. Walter Benjamin: culturas de la imagen, ed. A. Uslenghi. Buenos Aires: Eterna Cadencia Editora, 2010. 53-74.

Habermas, Jürgen. "Walter Benjamin: Consciousness-Raising or Rescuing Critique (1972)." En On Walter Benjamin. Critical Essays and Recollections, ed. G. Smith. Cambridge, Massachusets and London: The MIT Press, 1988. 90-128.

Hofmannsthal, Hugo von. Poesía lírica seguida de "Carta de Lord Chandos." España: Igitur/poesía, 2002

Huyssen, Andreas. "Las miniaturas modernistas: instantáneas literarias de espacios urbanos." En Andreas Huyssen, Modernismo después de la modernidad. Buenos Aires: Gedisa, 2010. 117125.

Michael Jennings. "Walter Benjamin y la Vanguardia Europea". En Cohen, M. y otros. Walter Benjamin: culturas de la imagen, ed. A. Uslenghi. Buenos Aires: Eterna Cadencia Editora, 2010. 25-52.

Kafka, Franz. Aforismos de Zürau, ed. R. Calasso. Madrid: Sexto Piso, 2005 [2004].

Kang, Jae-Ho. The Phantasmagoria of Spectacle - A Critique of Media Culture. En Walter Benjamin and Actualities of Aura, eds. E. Steinskog y P. Dag. Copenhagen: NSU Press, 2005.

Lash, Scott. Crítica de la Información. Buenos Aires: Amorrortu, 2005.

López Cuenca, Alberto. "Formas de vida: de Wittgenstein a las Comunidades Electrónicas". A Parte Rei. Revista de Filosofía. [En línea] núm. 56 (marzo de 2008): http://serbal.pntic.mec.es/ AParteRei/cuenca56.pdf (Acceso: 10 de octubre de 2104).

McLuhan, Marshall y Fiore, Quentin. El Medio es el Masaje. Un inventario de efectos. Barcelona: Paidós, 1997. 
Mancini, Adriana. Introducción. En Denkbilder. Epifanías en viajes, por W. Benjamin, Buenos Aires: El cuenco de plata, 2011. 7-19.

Marchessault, Janine. Marshall McLuhan. London: Sage, 2005.

Markus, Gyorgy. "Walter Benjamin or The Commodity as Phantasmagoria”. New German Critique. Special Issue on Walter Benjamin, núm. 83 (2001): 3-42.

Roncallo-Dow, Sergio. Más allá del espejo retrovisor. La noción de medio en Marshall McLuhan. Bogotá: Pontificia Universidad Javeriana, 2011.

Roncallo-Dow, Sergio. "Marshall McLuhan. El medio (aún) es el mensaje 50 años después de Understanding Media." Palabra Clave, 17(3), (2014): 582-588.

Sarlo, Beatriz. Siete ensayos sobre Walter Benjamin. Argentina: Fondo de Cultura Económica, 2007 [2000].

Strate, Lance. "Estudiar los medios como medios: McLuhan y el enfoque de la ecología de los medios". En Ecología de los medios. Entornos, evoluciones e interpretaciones, ed. C. A. Scolari. Barcelona: Paidós, 2015. 120-134.

Wittgenstein, Ludwig. Investigaciones filosóficas. México: UNAM-Universidad Nacional Autónoma de México, 2003 [1988 (1958)].

Wittgenstein, Ludwig. Los cuadernos azul y marrón. Madrid: Tecnos, 2009 [1968].

Zegarra, Raúl. Walter Benjamin y la transformación de nuestra experiencia del mundo. Sagrada Anarquía. [En línea] sagradanarquia.wordpress.com/2009/07/18/walter-benjamin-y-latransformacion-de-nuestra-experiencia-del-mundo-i/. (Acceso: 19 de julio de 2009).

\section{Cómo citar este artículo:}

Roncallo Dow, S. y Mazorra, D. “Lenguaje, tweets y pantallas. Entre escrituras y visualidades". Cuadernos de Música, Artes Visuales y Artes Escénicas, 10(2) 153-169, 2015. http://dx.doi. org/10.11144/Javeriana.mavae10-2.Itpe 
